\title{
Determinants of pollution: what do we really know?
}

\author{
By Martin Gassebner*, Michael J. Lamla $†$, and Jan-Egbert Sturm
}

${ }^{\star}$ KOF Swiss Economic Institute, ETH Zurich, Switzerland

$\dagger$ KOF Swiss Economic Institute, ETH Zurich, Weinbergstrasse 35, 8092 Zurich, Switzerland; e-mail: lamla@kof.ethz.ch

$\$$ KOF Swiss Economic Institute, ETH Zurich, Switzerland, and CESifo, Munich, Germany

\begin{abstract}
The recent literature proposes many variables as significant determinants of pollution. This paper gives an overview of this literature and asks which of these factors have an empirically robust impact on water and air pollution. We apply Extreme Bound Analysis (EBA) on a panel of up to 120 countries covering the period 1960-2001. We find supportive evidence of the existence of the environmental Kuznets curve for water pollution. Furthermore, mainly variables capturing the economic structure of a country affect air and water pollution.
\end{abstract}

JEL classifications: C23, F59, L60, O13, Q53.

\section{Introduction}

Faced with a rapidly growing population and increasing economic activity over the last several decades, policy-makers around the world have devoted more and more attention to the problem of pollution. It is therefore not surprising that many economists have joined the search for the underlying causes of the observed environmental degradation. Earlier studies have identified production and production-specific variables as determinants of pollution.

Among these types of variables, GDP per capita is at a center of focus. Most authors nowadays believe that its relationship to pollution is non-linear: the effect on the environment is negative at early stages of development, but after a certain threshold a higher degree of industrialization has a positive effect. Grossman and Krueger (1995) and Selden and Song (1994) were amongst the first to examine this particular relationship, which the latter labeled the environmental Kuznets curve (EKC).

Another line of literature discusses the impact of globalization on pollution. On the one hand, intensive trade patterns accelerate efficient allocations which in turn 
might lead to lower levels of pollution (e.g., Cole, 2004). On the other hand, the so-called pollution haven hypothesis states that globalization causes dirty industrial sectors to be located in countries with low environmental standards (e.g., Birdsall and Wheeler, 1993).

Lately, political indicators have been introduced into the discussion; the constitutional set-up of a country may explain different levels of pollution, as it relates to economic and political freedom (e.g., Carlsson and Lundström, 2003; Neumayer, 2003; Bernauer and Koubi, 2009).

Authors like Torras and Boyce (1998) as well as Cole and Neumayer (2004) indicate that demographic factors induce different patterns in pollution levels. For instance, in urban areas lifestyles are bound to differ from those in more rural regions; these differences in lifestyle might imply differences in environmental pollution.

The existing empirical literature on the determinants of pollution suffers from several drawbacks. First, as stated above, a wide variety of variables has been suggested as explaining environmental contamination and there is little consensus in the literature on which of these variables really matter. Second, most authors do not carefully examine the sensitivity of their empirical findings. Thus, it is hard to tell whether the variables reported to be significant in a particular regression remain robust determinants of pollution once other potentially important explanatory variables are included. ${ }^{1}$ Third, the majority of publications only focuses on one particular hypothesis and limits the number of control variables; no systematic analysis of the different hypotheses mentioned in the literature is offered. Hence, possible interdependencies with other variables and potential omitted variable biases are generally neglected. A final drawback of some studies is the limited data sample. Often estimations are conducted for only one country over several years, or for only one year over a cross-section of countries.

The aim of this article is to analyse to what extent various economic, political, and demographic variables that have been suggested in the literature are robust determinants of water and air pollution. For this purpose, we first provide a detailed overview of the literature from which we subsequently derive a list of 19 explanatory variables. We then estimate a panel data model including up to 120 countries for the period 1960-2001 and apply the so-called Extreme Bounds Analysis (EBA) to examine to what extent these variables are robust determinants of environmental degradation. To the best of our knowledge, this approach to check for the robustness of a relationship has not been used in this field of research before. It has been widely employed in, for instance, the economic growth literature (e.g., Levine and Renelt, 1992; Sala-i-Martin, 1997; Beugelsdijk et al., 2004; Sturm and de Haan, 2005). As pointed out by Temple (2000), presenting only the results of the model preferred by the author(s) of a particular publication can be

\footnotetext{
${ }^{1}$ This paper uses the term robustness to reflect the insensitivity of empirical findings with respect to one variable to changes in the set of conditioning variables.
} 
misleading. Extreme Bounds Analysis is a fairly neutral means to check robustness issues and compare the validity of conflicting findings in empirical research.

This article uses biochemical oxygen demand (BOD) as the measure of water pollution and carbon dioxide $\left(\mathrm{CO}_{2}\right)$ emissions and-to a lesser extent-sulfur dioxide $\left(\mathrm{SO}_{2}\right)$ as measures of air pollution. All three variables are widely accepted environmental proxies which have been well-documented over extended periods of time for most countries in the world.

For water pollution, we find support for the EKC hypothesis. For air pollution, results suggest that if a turning point exists it occurs at income levels that are not actually observed in the real world. Hence, we can only confirm a concave relationship between GDP per capita and $\mathrm{CO}_{2}$. It is therefore not clear that the world will be able to simply grow its way out of the greenhouse gas problem. Furthermore, air pollution is not robustly linked to most of our political-institutional variables directly, implying that no straightforward policy conclusions can be drawn.

The remainder of this paper is structured as follows. First, the relevant literature is reviewed and the variables on which we focus are introduced. Then, the methodological approach is discussed. Next, the results are reported and interpreted. The final section summarizes and concludes.

\section{Literature overview and variables selection}

Table A4 (in Appendix 2, available online) summarizes 16 studies on the determinants of pollution that have been published since the beginning of the 1990s. The papers were selected to maximize the number of potential determinants. The selection is by no means exhaustive. As the table makes clear, not only have previous studies introduced a wide array of explanatory variables, also well over 20 different measures of pollution have been used. The four most often used measures are $\mathrm{CO}_{2}$ and $\mathrm{SO}_{2}$ emissions (to proxy air pollution) plus BOD and the level of dissolved oxygen (to proxy water pollution).

As our measure of water pollution we take BOD from the World Development Indicators CD-ROM (2003) as published by the World Bank which covers the years 1980-2001 (see World Bank, 2003a). According to the European Environment Agency 'BOD is a measure of how much dissolved oxygen is being consumed as microbes break down organic matter. A high demand, therefore, can indicate that levels of dissolved oxygen are falling, with potentially dangerous implications for the river's biodiversity'. ${ }^{2}$ It is available for a maximum of 114 countries starting in 1980 , i.e., totaling roughly 2,000 observations. The data on water pollution are probably the most accurately measured pollution data, since sampling techniques are well understood and common in all countries. Additionally, data on water

${ }^{2}$ See http://www.eea.europa.eu/data-and-maps/indicators/biochemical-oxygen-demand-in-rivers. 
pollution are more readily available than other emissions data as most industrial pollution control programs start by regulating emissions of organic water pollutants. Since the level of dissolved oxygen is basically the reciprocal to BOD but not as readily available for as many countries, we choose to exclude this measure.

With respect to air pollution, our main variable of interest is the level of $\mathrm{CO}_{2}$ emissions also reported in World Bank (2003a). ${ }^{3}$ It is available for up to 188 countries covering 1960-99 with a total of over 6,500 observations. Unfortunately, these data are (necessarily) based on estimates and not measured directly. Originally, the data stem from the Carbon Dioxide Information Analysis Center (CDIAC). Accordingly, '[t]hese calculations are derived from data on fossil fuel consumption, based on the World Energy Data Set maintained by the UNSD and from data on world cement manufacturing based on the Cement Manufacturing Data Set maintained by the US Bureau of Mines' (World Bank, 2003b, p.245-6). Keeping this caveat in mind, these are likely to be the best data available for a large set of countries.

We have also included $\mathrm{SO}_{2}$ emissions as a pollutant in our set-up. The latest and largest data source on $\mathrm{SO}_{2}$ is Stern (2005b) To construct the data set Stern has combined various sources and used different methods: 'For the remaining countries and for missing years for countries with some published data, [he] interpolate[s] or extrapolate[s] estimates using either an econometric emissions frontier model, an environmental Kuznets curve model, or a simple extrapolation, depending on the availability of data' (Stern, 2005b, p.163). This data gives a decent overview of the evolution of sulfur emission during the past decades for a substantial part of the world. However, using estimation procedures in the data generating process calls for caution in this part of our analysis and, hence, we will not concentrate upon those results. ${ }^{4}$

We will henceforth focus on the results using $\mathrm{BOD}$ and $\mathrm{CO}_{2}$ to proxy water and air pollution, respectively. To capture size effects we scale our pollution measures by population and subsequently take natural logarithms. With a correlation coefficient of 0.762 water and air pollution are strongly related to each other (see Table A2 in Appendix 1). Further evidence for strong comovement is presented in Fig. 1 showing a plot of the levels of water against air pollution for the year 1995.

The next step is to select our list of explanatory variables. For that we conduct an extensive literature survey. Based upon these previous studies, Table A4 (in Appendix 2, available online) points out that a rather large and heterogeneous set of variables has been suggested in the past. Furthermore, the empirical results for particular variables are rather mixed. The remainder of this section describes the

\footnotetext{
${ }^{3}$ Unless mentioned otherwise, all data stem from World Bank (2003a) to ensure consistency.

${ }^{4}$ For reason of comparison, we have summarized the $\mathrm{SO}_{2}$ results in Table $\mathrm{A} 3$ in Appendix 2, available online.
} 


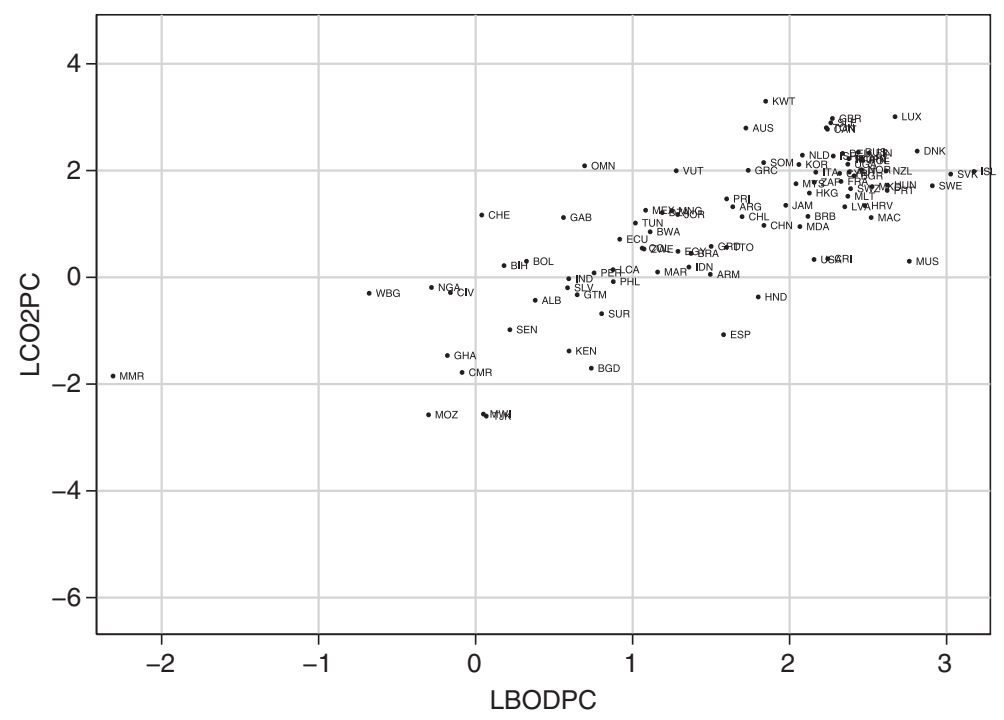

Fig. 1 Water and air pollution in 1995

Note: The three letter country codes refer to the World Bank classification. Air pollution is proxied by $\log$ per capita $\mathrm{CO}_{2}$ emissions while water pollution is measured by the log of per capita biological oxygen demand.

19 variables and their underlying hypotheses, which we have distilled out of this literature for further use in our own empirical analysis.

From a theoretical point of view, the environmental Kuznets curve (EKC) is the most prominent hypothesis. Instead of an inverted U-shaped relationship between income inequality and per capita income-as suggested by Kuznets (1955)—-the EKC presumes such a relationship between per capita emissions and per capita income.

A vast number of theories have been proposed that lead to such an inverted U-shaped relationship, each of them relying on specific assumptions. Since it is beyond the scope of this paper to discuss these various set-ups, we restrict our focus to the models of Grossman and Krueger (1995), Antle and Heidebrink (1995), and Torras and Boyce (1998).

Grossman and Krueger discriminate between a scale, a composition, and a technology effect of growth on the environment. The scale effect describes the economic degradation due to a boost in economic activity. If economic activity is increasing, more resources are used for production and, hence, more dissipation occurs. The composition effect describes the change in economic structures caused by growth. For instance, the transition from an industrial society to a service-based one is likely to have a positive effect on its environmental quality. An example of a negative effect of a change in demand patterns on the environment is given by Chamon et al. (2008) who show that car ownership increases rapidly once income rises above 
a threshold. ${ }^{5}$ Finally, the technology effect specifies the substitution of obsolete, dirty, and inefficient technology by more sophisticated and 'cleaner' methods.

Other studies argue that the income elasticity of environmental demand is changing, see, e.g., Antle and Heidebrink (1995). As income grows, a higher standard of living is achieved which might lead individuals to care more about environmental protection. In most societies, this changing attitude will have an impact on actual environmental policy.

Moreover, Torras and Boyce (1998) use sufficiently functioning markets as an explanation for the environmental Kuznets curve. Early stage industries are characterized by heavy exploitation of natural resources. This in turn significantly reduces the available stock of resources. Conditioning on an effective market mechanism in pricing resources, a consequence of such exploitation will be rising prices. Higher prices increase pressure to switch to less resource-intensive technologies. Again this leads to a hump-shaped relationship between pollution and income. ${ }^{6}$

Studies like Shafik (1994), Selden and Song (1994), and Grossman and Krueger (1995) report empirical evidence in favour of the EKC. ${ }^{7}$ However, results presented by, e.g., Arrow et al. (1995) indicate that this finding is not necessarily robust. ${ }^{8} \mathrm{We}$ use the level, squared, and cubic transformations of (the log of) real GDP per capita (LGDPPC, LGDPPC ${ }^{2}$, LGDPPC ${ }^{3}$ ) to test the EKC theory. ${ }^{9}$

According to, e.g., Cole (2004), trade may reduce pollution emissions due to greater competitive pressure or 'greater access to 'greener' production technologies' (p.79). ${ }^{10}$ For that reason we introduce a variable representing trade intensity in our analysis. This variable (TRADE) is defined as the ratio of imports plus exports over GDP.

Often the trade effect is disaggregated into three components: a scale effect, a technique effect, and a composition effect. The scale effect refers to the fact that trade increases market size which presumably increases production and in turn increases pollution. The technique effect relates to the trade-induced changes of

\footnotetext{
${ }^{5}$ We owe this example to an anonymous referee.

${ }^{6}$ The argument of Torras and Boyce (1998) may be less applicable to our setting. Prices of resources are most likely determined on world markets. Thus domestic markets may only play a minor role in determining domestic demand.

${ }^{7}$ For a detailed survey of theoretical and empirical studies dealing with the EKC, we refer to Dinda (2004).

${ }^{8}$ Some authors propose an inverted N-shaped or even a N-shaped relationship. See, e.g., Holtz-Eakin and Selden (1995). However, often the additional turning point is out-of-sample.

${ }^{9}$ Recently semi- and non-parametric specifications of the EKC have emerged, see, e.g., Millimet et al. (2003) and Azomahou et al. (2006). These studies find an EKC shape very similar to ours, but often fail to include relevant conditioning variables. We refer to Maddison (2006) for a spatial modeling approach of the EKC.

${ }^{10}$ This is in line with Frankel and Rose (2005) who find that trade tends to reduce pollution even after taking into account potential simultaneity problems. However, in the case of $\mathrm{CO}_{2}$ emissions, the same authors point toward a positive relationship. They argue that this is due to the global externality feature of that form of pollution.
} 
the production technology. The composition effect stems from changes in the country-specific composition of production caused by international specialization. When the latter is associated with cross-country differences in environmental regulation, it is commonly labeled the pollution haven hypothesis. Countries with a comparative disadvantage in 'dirty' production, i.e., with strict environmental regulations, will-according to this hypothesis-outsource pollution-intensive activities. This will increase trade between nations with different comparative advantages (Birdsall and Wheeler, 1993; Mani and Wheeler, 1998). ${ }^{11}$

Mainly because micro data is needed to analyse systematically which type of industry has been shifted across borders, it is quite difficult to test this hypothesis empirically. Hence, most studies end up concluding that their results do not necessarily confirm or reject the pollution haven hypothesis. Of the remaining ones, not many are affirmative. For instance, Jaffe et al. (1995) and Cole (2004) find no evidence in favour of this hypothesis. Since it is virtually impossible to get the adequate micro data that match our otherwise aggregated information, we will also not be in a position to address this question fully. As the scale, technique, and composition effects do not all point in the same direction, the overall impact of trade on the environment is ambiguous.

In a similar vein, international capital transactions might also affect national pollution levels. Following Antweiler et al. (2001) we therefore include inward foreign direct investment as a percentage of GDP (FDIGDP) in our analysis. ${ }^{12}$

Carlsson and Lundström (2003) propose to include real GDP growth (GDPGR). In our panel data set-up with annual observations, this variable captures the business cycle of a country.

Income inequality plays a controversial role in the literature. The ambiguity is highlighted by McAusland (2003). According to her theoretical model the effect of inequality on the environment depends on the ownership distribution behind inequality and can thus be either beneficial or detrimental. ${ }^{13}$ The empirical literature is ambiguous. Torras and Boyce (1998) argue that asset ownership of high income inhabitants yields a net increase in economic growth, i.e., more pollution. As this group possesses both substantial economic as well as political power, greater

\footnotetext{
${ }^{11}$ Copeland and Taylor (2004) make a distinction between the pollution haven hypothesis, which is the hypothesis that a reduction in trade barriers will cause a shift of polluting industries to countries with weaker regulations and the pollution haven effect, which suggests that weaker environmental regulations will affect trade flows.

${ }^{12}$ Cole et al. (2006) extend the pollution haven hypothesis literature to FDI and examine whether it influences environmental regulation.

${ }^{13}$ In case large but poor parts of society own shares of firms using clean technologies, more inequality might actually lead to an improvement of the environment. However, the overall sign of the relationship also depends upon the terms of trade. McAusland (2003) assumes that in a closed economy pollution policy would make dirty goods more expensive and hence alter the terms of trade between dirty and clean goods. A majority of the poor owning clean capacities would thus prefer a less stringent policy. Nevertheless, assuming an open economy facing fixed world prices, the same majority would prefer more stringent policies in order to keep the terms of trade stable.
} 
inequality leads to more pollution. A contrasting finding is presented by Gassebner et al. (2008). They show both theoretically and empirically that the declining economic significance of the industrial sector, associated with falling industrial income shares and a lower political weight of blue-collar workers, tends to increase environmental regulation and thereby leads to less pollution.

Hence, we introduce the variable INEQUAL. It is taken from the University of Texas Inequality Project (2001) and is based on the United Nations International Development Organization's (UNIDO) database of payments. The income inequality measure is derived from the between-groups component (measured across industry sectors within each country) of Theil's T statistic. ${ }^{14}$ As individual data are often not available, the sum of the between group elements is a reasonable lower bound for Theil's $\mathrm{T}$ statistic in the population. ${ }^{15}$

Carlsson and Lundström (2003) introduce the indices of economic freedom (ECFREE) and political freedom (POLFREE) as potential determinants of pollution. ${ }^{16}$ They claim that economic freedom leads to a more efficient allocation of resources and therefore to a lower level of emissions. The intuitive reasoning behind POLFREE is that it is easier for people to express their preferences for higher environmental standards in a politically more open system.

Other politically motivated variables included in our analysis are a dummy variable measuring whether or not the party of the chief executive has a leftwing orientation (LEFT), the number of years the chief executive has been in office (YRSOFFC), a dictatorship dummy (DICT), and a second measure of democracy (DEMOC). Our variable LEFT is adapted from Neumayer $(2003,2004)$ who suggests that despite more traditional political objectives, generally driven by bluecollar workers' interests, a higher degree of sympathy for environmental protection by left-wing governments is possible. ${ }^{17}$ The next two variables, YRSOFFC and DICT, are suggested by Klick (2002). First, he reasons that the longer a government is in power the less willing it is to enhance pollution controls as it faces diminishing returns of staying in power over time. Second, he claims that a dictator might take care of the environment to secure his leading position; a dictator has a limited number of instruments at hand to remain in power and might have stronger incentives to invest in environmental protection rather than, e.g., schooling. ${ }^{18}$

\footnotetext{
${ }^{14}$ The between-groups component equals $\sum p_{j} \mu_{j} / \mu \log \left(\mu_{j} / \mu\right)$ where $p_{j}$ is the employment share and $\mu_{j}$ and $\mu$ reflect the group average and population income, respectively.

${ }^{15}$ For more details see http://utip.gov.utexas.edu/. For an overview on the different inequality measures including the Theil inequality measure, see http://utip.gov.utexas.edu/tutorials/intro_ineq_studies.ppt.

${ }^{16}$ We retrieve both indicators from Gwartney et al. (2003) and Freedom House (1999), respectively. POLFREE is the average of the two Freedom House indices, i.e., civil liberties and political rights.

${ }^{17}$ Neumayer, among other things, argues that especially the poor and the working class suffer from environmental degradation.

${ }^{18}$ The variable DICT is calculated out of the Executive Indices of Electoral Competitiveness (EIEC) included in the Database of Political Institutions as collected and described by Beck et al. (2001).
} 
On the other hand, Congleton (1992) contends that autocratic countries should have lower environmental standards. He believes that autocratic rulers have a shorter time horizon. Consequently, their incentives to invest in environmental protection are lower. To test his hypothesis Congleton includes the democracy score from the Polity IV database (Gurr et al., 2003) which we also add to our list of variables as DEMOC. Because of the relatively low correlation between DEMOC and POLFREE and their somewhat different focus we include both measures in our set-up. ${ }^{19}$

Pollution might also be related to the level of education in a country. Torras and Boyce (1998) as well as Klick (2002) include measures of education as control variables in their respective set-up. In the spirit of Lipset (1959), who argues that education is at least a necessary condition for democracy, higher education can be considered a prerequisite for a higher demand for a clean environment. We include both primary education (PRIMEDU) and the illiteracy rate among adults (ILLIT) in our set-up.

Following, e.g., Klick (2002) and Borghesi (2006), we include (the log of) population density (LPOPDENS). The effect of this variable is a priori ambiguous, however. On the one hand, if more people live in a given area the effect of individual pollution aggravates. Thus a high population density may lead to more pollution. On the other hand, Stern (2005a) argues that a higher population density may lead to lower per capita pollution emissions; as more people are potentially affected by pollution the benefit of abatement increases.

As a second demographic variable, we use the share of urban population in total population (URBAN). Cole and Neumayer (2004) argue that means of transports, like cars, buses, etc., are more intensively used in urbanized areas as compared to rural parts of a country. Moreover, food and other consumer goods have to be transported into cities. Both examples suggest higher levels of pollution in an economy that is more urbanized. On the other hand, citizens living in urbanized areas are directly exposed to industrial pollution and therefore political pressure to reduce pollution might rise (Damania et al., 2003).

The industrial sector is usually considered to generate more pollution than the service sector. For that reason, Neumayer (2003) argues that the industry share can help to explain the level of pollution in a country. We introduce such an industrialization measure both in terms of output (INDSHGDP) as well as in terms of labour input (INDSHEMP) in our analysis. Although at first glance it might seem that these two variables quantify the same concept, this need not necessarily be the case. From a theoretical stance, INDSHGDP measures the relative importance of

\footnotetext{
${ }^{19}$ For a discussion on the difference between the two democracy measures see Aidt and Gassebner (2010) and Vreeland (2008).
} 
the manufacturing sector in an economy. ${ }^{20}$ When controlling for this, INDSHEMP can be interpreted as measuring the labour intensity of the industry sector. Especially due to technological changes these two variables do not have to move in parallel. For instance, assume that a technological shock increases productivity per worker. If employment remains unaltered then INDSHEMP is unaffected. However, INDSHGDP rises in this case. This theoretical reason is reinforced by a rather low correlation coefficient of 0.375 between these two measures (see Table A2 in Appendix 1). ${ }^{21}$ INDSHEMP may also account for the pressure from industrial workers for lower regulations and hence could lead to a higher level of pollution (Damania et al., 2003; Gassebner et al., 2008).

Besides the degree of industrialization, the composition of a country's energy sector might play an important role. In line with Neumayer (2003), we therefore include the share of electricity production from oil sources in total electricity production (OILENERGY). ${ }^{22}$ Neumayer (2003) includes the amount of commercial energy used to produce one dollar of output. Conditioning on the characteristics of an economy, this variable proxies for the level of energy efficiency in the production process. However, if an EKC exists it most likely would work through altering the amount of energy used per one dollar of output. Hence we opt to exclude this variable from our analysis. $^{23}$

As a final economic structure variable, we include (the log of) the use of fertilizer (LFERT) into our list of potential explanatory variables. Cole and Elliott (2003) suggest that higher fertilizer consumption increases the level of water pollution. Besides the straightforward effect that fertilizer has on water pollution, it seems reasonable to assume that it may also help explain the level of air pollution. First, one can interpret this variable as a measure of the general attitude toward environmental protection. For instance, in an economy that heavily uses fertilizer, the awareness level of carbon dioxide produced by cars, by burning oil, etc., might not be very high either. Another aspect, which seems predominant in low income countries, is that producing fertilizer is a plain but very pollutive production process. The presence of such 'dirty' industries increases both water and air pollution.

This leaves us with a list of 19 explanatory variables covering in total up to 120 countries over the period 1960-2001. For a complete overview concerning sources and specification of the variables we refer to Table A1 (in Appendix 1).

\footnotetext{
${ }^{20}$ It would also be interesting to have a closer look at non-manufacturing industrial GDP as this often includes potentially dirty sectors such as mining and power generation. However, lack of data forces us to concentrate on manufacturing industrial GDP.

${ }^{21}$ The low correlation is not driven by the use of panel data. We check this by calculating the correlations of the between and within components. The resulting correlation are 0.47 and 0.46 , respectively.

${ }^{22}$ Obviously oil is neither the only nor the most polluting energy source used in electricity production. However, data limitations force us to restrict our attention to oil.

${ }^{23}$ We thank an anonymous referee for this suggestion. In a previous working paper version of this paper, Gassebner et al. (2006), we included energy use per unit of GDP. The empirical relevance of the EKC hypothesis is not fundamentally affected by this.
} 


\section{Model}

We employ (variants of) the so-called Extreme Bounds Analysis (EBA) as suggested by Leamer (1983) and Levine and Renelt (1992) to examine which explanatory variables are robustly related to our dependent variables. To the best of our knowledge, this has never been done before in this line of literature, although there are some very good reasons to apply this methodology. ${ }^{24}$

EBA has been widely used in the economic growth literature. The central difficulty in that line of research — which also applies to the literature on the determinants of pollution-is that several different models may all seem reasonable, but yield different conclusions about the parameters of interest. Indeed, a glance at the studies summarized in Table A4 (in Appendix 2, available online) illustrates this point. The results of these studies sometimes differ substantially. At the same time, most authors do not offer a careful sensitivity analysis to examine how robust their conclusions are.

The EBA can be exemplified as follows. Equations of the following general form are estimated:

$$
Y=\alpha M+\beta F+\gamma Z+u
$$

where $Y$ is the dependent variable; $M$ is a vector of 'standard' explanatory variables; $F$ is the variable of interest; $Z$ is a vector of up to three possible additional explanatory variables (following Levine and Renelt, 1992), which according to the literature may be related to the dependent variable; and $u$ is an error term. The extreme bounds test as originally proposed by Leamer (1983) for variable $F$ says that if the lower extreme bound for $\beta$-i.e., the lowest value for $\beta$ minus two standard errors - is negative, while the upper extreme bound for $\beta$-i.e., the highest value for $\beta$ plus two standard errors-is positive, $Y$ is not robustly related to the variable $F$.

As argued by Temple (2000), it is rare in empirical research that we can say with certainty that some model dominates all other possibilities in all dimensions. In these circumstances, it makes sense to provide information about how sensitive the findings are to alternative modeling choices. While EBA provides a relatively simple means of doing exactly this, it has been criticized in the literature.

Sala-i-Martin (1997) rightly argues that the test applied in the Extreme Bounds Analysis is too strong. If the distribution of the parameter of interest has some positive and some negative support, then one is bound to find one regression for which the estimated coefficient changes sign if enough regressions are run. We will therefore not only report the extreme bounds, but also the percentage of the

\footnotetext{
${ }^{24}$ Bayesian Averaging of Classical Estimates (BACE) as introduced by Sala-i-Martin et al. (2004) is a somewhat more sophisticated method. The idea builds on Raftery (1995) and Raftery et al. (1997). However, because of the prerequisite of strongly balanced data it is not feasible in our setting. For studies on pollution using means of Bayesian Model Averaging we refer to Begun and Eicher (2008) and Lamla (2009).
} 
regressions in which the coefficient of the variable $F$ is statistically different from zero at the 5\%-level. Moreover, instead of analysing just the extreme bounds of the coefficient estimates of a particular variable, we follow Sala-i-Martin's suggestion and analyse the entire distribution. We also report the unweighted parameter estimate of $\beta$ and its standard deviation, as well as the unweighted cumulative distribution function $(\operatorname{CDF}(0))$. The latter shows the fraction of the cumulative distribution function lying on each side of zero. $\operatorname{CDF}(0)$ indicates the larger of the areas under the density function either above or below zero; in other words, regardless of whether this is $\operatorname{CDF}(0)$ or $1-\operatorname{CDF}(0)$. So $\operatorname{CDF}(0)$ will always be a number between 0.5 and 1.0. However, in contrast to Sala-i-Martin, we use the unweighted instead of the weighted $\operatorname{CDF}(0)$. The criterion for considering a variable to be robustly related to a pollution measure is the $\operatorname{CDF}(0)$ value. Sala-iMartin (1997) suggested considering a variable to be robust if the $\operatorname{CDF}(0)$ criterion is greater than 0.90 . Instead we follow Sturm and de Haan's (2005) proposal to use a stricter threshold value of 0.95 to take account of the two-sided nature of the test.

Another objection to the EBA is that the initial partition of variables in the $M$ and in the $Z$ vector is likely to be rather arbitrary. Still, as pointed out by Temple (2000), there is no reason why standard model selection procedures (such as testing down from a general specification) cannot be used in advance to identify variables that seem to be particularly relevant. Furthermore, some variables are included in the large majority of studies and are by now rather common in the pollution literature. Using a combination of general-to-specific modeling and theoretical considerations, we started with all 21 explanatory variables listed in Table A1 (in Appendix 1) to set up our baseline model.

In our view, the inclusion of GDP variables in the $M$ vector to capture the EKC argument is evident. Even if one does not believe in the EKC in a strict sense it is rather likely that production of goods and services leads to pollution. In the literature the functional form of the EKC sometimes differs. For that reason, we have checked whether the relationship is linear, quadratic (hump-shaped relationship) or of an even higher order (inverted N-shape relationship). Our results clearly suggest the need of a quadratic term when describing the relationship between GDP and especially water pollution. Hence, we are able to confirm an inverted U-shaped relationship. Given the better fit to the data when using the squared specification, we leave out the cubic term.

\section{Results}

An important step in qualifying the robustness of our estimation output is to discuss causality and endogeneity aspects. So far, no study in the EKC literature that we are aware of dwells upon this topic. In our view, an effective way of evaluating the relevance of this problem is to utilize lagged explanatory variables.

When we run the EBA employing lagged variables the results remain virtually unchanged as compared to the outcomes with contemporaneous variables. Correlation coefficients comparing the results of the two variable sets range 
between 0.95 to 0.99 . It leads us to conclude that endogeneity is in our case not of major importance. Furthermore, as the significance of the proposed variables increases on average when using lagged values, causality seems to point in the desired direction. In the remainder we will concentrate on the results when using lagged variables. ${ }^{25}$ Further robustness tests on our EBA results will be presented at the end of this section.

Before turning to the regression results, we first check for stationarity of our dependent variables by using the test proposed by Maddala and $\mathrm{Wu}$ (1999). In each case, we can clearly reject the null hypothesis of non-stationarity. ${ }^{26}$ To ensure the generality of our results, we follow the most rigorous empirical approach and run our analysis using fixed country and year effects as well as clustered standard errors.

To check the robustness of the baseline model with respect to model specification all combinations of up to three variables out of the remaining 18 variables are added. The top part of Tables 1 and 2 summarize the results of these of 1,159 combinations for the baseline model. The variables are sorted according to the estimated $\mathrm{CDF}(0)$ values. Both GDP variables are highly significant according to the $\operatorname{CDF}(0)$ criterion of Sala-i-Martin (1997) for BOD while the evidence of the robustness of the squared GDP term is mixed for $\mathrm{CO}_{2}$.

The EBA results for the baseline model strongly support the EKC hypothesis in particular for water pollution. The negative coefficient of squared GDP per capita suggests that there indeed exists a non-linear relationship between per capita GDP and both pollution variables. ${ }^{27}$ To validate an inverted U-shape relationship, we need to know whether or not the implied turning point is within sample. Therefore, for both models, we calculate the implied EKC-turning point for each of the 1,159 regressions. In this way, we are able to give a much more detailed assessment of the EKC-turning point as commonly done in this line of literature.

Most of the turning points for $\mathrm{CO}_{2}$ are far out of sample (see Table 3 for the descriptive statistics). Hence, at least within sample, the relationship between $\mathrm{CO}_{2}$ emissions and GDP per capita is rather concave than of an inverted U-shape nature. Figure 2 shows the histogram of the turning points for water pollution. It is based on 1,159 point estimates and can be interpreted as a graphical approximation of the distribution of turning points when all estimated models receive an equal weight. In line with Cole (2004), we find the median turning point for BOD_at a GDP per capita level of approximately 26,800 US \$ (measured in constant 1995 prices) - to be in-sample. It seems that, since water pollution has somewhat less of an international public good character and becomes apparent much sooner than $\mathrm{CO}_{2}$

\footnotetext{
${ }^{25}$ Results using contemporaneous variables are available upon request.

${ }^{26}$ The test statistics and p-values are: $L C O_{2} P C, \quad \chi^{2}(376)=742.07, \quad$ p-value $=0.00 ; \quad L S O_{2} P C$, $\chi^{2}(340)=491.80, \mathrm{p}$-value $=0.00 ; L B O D P C, \chi^{2}(284)=405.82, \mathrm{p}$-value $=0.00$.

${ }^{27}$ Throughout the remainder of the paper when interpreting the effect of an explanatory variable, we are, due to our set-up, speaking of lagged effects. However, in order to enhance readability, we do not explicitly state this every time.
} 
Table 1 Extreme Bounds Analysis for water pollution with lagged explanatory variables

\begin{tabular}{|c|c|c|c|c|c|c|c|}
\hline Variable & $\begin{array}{l}\text { Lower } \\
\text { bound }\end{array}$ & $\begin{array}{l}\text { Upper } \\
\text { bound }\end{array}$ & \%Sign. & $\begin{array}{l}\text { Unwght. } \\
\mathrm{CDF}(0)\end{array}$ & $\begin{array}{c}\text { Unwght. } \\
\boldsymbol{\beta}\end{array}$ & $\begin{array}{l}\text { Std. } \\
\text { error }\end{array}$ & $\begin{array}{l}\text { Impact } \\
\text { rank }\end{array}$ \\
\hline $\begin{array}{l}\text { Base model } \\
\text { LGDPPC1 }\end{array}$ & -3.012 & 6.968 & 91.56 & 0.9813 & 1.792 & 0.657 & - \\
\hline $\begin{array}{l}\text { LGDPPCSQ1 } \\
\text { Extended model }\end{array}$ & -0.406 & 0.265 & 77.70 & 0.9518 & -0.088 & 0.041 & - \\
\hline INDSHEMP1 & -0.020 & 0.050 & 96.86 & 0.9933 & 0.017 & 0.004 & 2 \\
\hline INEQUAL1 & -0.066 & 0.032 & 92.71 & 0.9847 & -0.021 & 0.008 & 4 \\
\hline ECFREE1 & -0.094 & 0.260 & 74.47 & 0.9609 & 0.063 & 0.032 & 8 \\
\hline URBAN1 & -0.029 & 0.099 & 69.91 & 0.9332 & 0.019 & 0.010 & 1 \\
\hline INDSHGDP1 & -0.043 & 0.044 & 45.09 & 0.8615 & 0.010 & 0.007 & 6 \\
\hline LEFT1 & -0.159 & 0.276 & 44.07 & 0.8497 & 0.037 & 0.028 & 15 \\
\hline DEMOC1 & -0.032 & 0.084 & 17.22 & 0.8207 & 0.011 & 0.011 & 9 \\
\hline DICT1 & -0.603 & 0.153 & 22.90 & 0.7903 & -0.054 & 0.049 & 14 \\
\hline LFERT1 & -0.240 & 0.402 & 23.40 & 0.7893 & 0.051 & 0.048 & 5 \\
\hline YRSOFFC1 & -0.018 & 0.032 & 7.70 & 0.7851 & 0.003 & 0.004 & 13 \\
\hline POLFREE1 & -0.114 & 0.126 & 6.89 & 0.7432 & 0.018 & 0.020 & 11 \\
\hline PRIMEDU1 & -0.022 & 0.022 & 7.40 & 0.7216 & 0.002 & 0.003 & 10 \\
\hline TRADE1 & -0.006 & 0.009 & 9.83 & 0.6399 & 0.001 & 0.001 & 12 \\
\hline OILENERGY1 & -0.009 & 0.007 & 3.95 & 0.6089 & 0.000 & 0.001 & 16 \\
\hline GDPGR1 & -0.037 & 0.015 & 5.57 & 0.6075 & -0.002 & 0.002 & 17 \\
\hline FDIGDP1 & -0.076 & 0.043 & 6.28 & 0.5915 & 0.000 & 0.007 & 18 \\
\hline ILLIT1 & -0.126 & 0.066 & 6.89 & 0.5069 & -0.003 & 0.014 & 7 \\
\hline LPOPDENS1 & -1.791 & 5.117 & 7.50 & 0.5010 & 0.123 & 0.448 & 3 \\
\hline
\end{tabular}

Note: The dependent variable is water pollution (LBODPC). Results based on 1,159 (base model) and 987 (extended model) regressions respectively using country- and time-specific random effects. '\%Sign.' refers to the percentage of regressions in which the respective variable is significant at a $5 \%$ significance level. 'Impact rank' lists the variables in descending order according to the impact resulting from a shock of one standard deviation. The standard deviation is calculated from the between component of the variables.

emissions, actions against water pollution are taken at a clearly earlier stage of economic development. Furthermore, the out-of-sample turning point for $\mathrm{CO}_{2}$ calls for an active environmental policy; we do not find support for the claim that one can simply 'grow out' of the problem. The global character of the greenhouse effect suggests that perhaps only international treaties in the spirit of the Kyoto Protocol are able to tackle the problem. ${ }^{28}$

\footnotetext{
${ }^{28}$ Our finding relates to the theoretical literature on the realization of international environmental agreements. Barrett (1994) and Rubio and Ulph (2006) find that there are no substantial gains from international cooperation if states are assumed to be identical. McGinty (2007) finds that once countries are heterogeneous, coordination leads to an overall higher level of abatement. Caplan et al. (2003) deals explicitly with the process of coalition formation and proposes to compensate countries initially unwilling to sign agreements such as the Kyoto Protocol to ensure participation.
} 
Table 2 Extreme Bounds Analysis for air pollution with lagged explanatory variables

\begin{tabular}{lccccccr}
\hline Variable & $\begin{array}{c}\text { Lower } \\
\text { bound }\end{array}$ & $\begin{array}{c}\text { Upper } \\
\text { bound }\end{array}$ & \%Sign. & $\begin{array}{c}\text { Unwght. } \\
\text { CDF(0) }\end{array}$ & $\begin{array}{r}\text { Unwght. } \\
\boldsymbol{\beta}\end{array}$ & $\begin{array}{c}\text { Std. } \\
\text { error }\end{array}$ & $\begin{array}{r}\text { Impact } \\
\text { rank }\end{array}$ \\
\hline Base model & & & & & & & \\
LGDPPC1 & -2.076 & 6.107 & 92.15 & 0.9820 & 1.577 & 0.525 & - \\
LGDPPCSQ1 & -0.331 & 0.193 & 50.30 & 0.8987 & -0.059 & 0.033 & - \\
Extended model & & & & & & & \\
LFERT 1 & -0.147 & 0.313 & 96.15 & 0.9928 & 0.111 & 0.033 & 2 \\
INDSHEMP1 & -0.051 & 0.047 & 93.31 & 0.9880 & 0.015 & 0.005 & 3 \\
DICT1 & -0.460 & 0.095 & 82.78 & 0.9704 & -0.095 & 0.044 & 11 \\
INEQUAL1 & -0.128 & 0.032 & 81.66 & 0.9603 & -0.013 & 0.005 & 5 \\
LPOPDENS1 & -1.094 & 2.922 & 55.42 & 0.9032 & 0.493 & 0.265 & 1 \\
LEFT1 & -0.094 & 0.315 & 40.93 & 0.8731 & 0.049 & 0.032 & 13 \\
INDSHGDP1 & -0.044 & 0.039 & 42.96 & 0.8388 & 0.007 & 0.006 & 7 \\
ECFREE1 & -0.134 & 0.324 & 15.91 & 0.8086 & 0.031 & 0.029 & 12 \\
TRADE1 & -0.007 & 0.019 & 17.63 & 0.8063 & 0.001 & 0.001 & 8 \\
URBAN1 & -0.033 & 0.040 & 21.48 & 0.7844 & 0.006 & 0.006 & 4 \\
OILENERGY1 & -0.005 & 0.010 & 17.02 & 0.7835 & 0.001 & 0.001 & 10 \\
PRIMEDU1 & -0.011 & 0.015 & 16.82 & 0.7732 & 0.002 & 0.002 & 9 \\
YRSOFFC1 & -0.015 & 0.032 & 13.88 & 0.7373 & 0.002 & 0.003 & 15 \\
DEMOC1 & -0.051 & 0.073 & 12.56 & 0.6335 & -0.005 & 0.012 & 14 \\
ILLIT1 & -0.075 & 0.102 & 2.84 & 0.6096 & 0.003 & 0.008 & 6 \\
GDPGR1 & -0.019 & 0.020 & 9.73 & 0.5970 & 0.001 & 0.002 & 17 \\
FDIGDP1 & -0.061 & 0.077 & 12.66 & 0.5534 & 0.001 & 0.007 & 16 \\
POLFREE1 & -0.109 & 0.126 & 4.56 & 0.5106 & 0.000 & 0.016 & 18 \\
\hline Note: The & & & & & & & \\
\hline
\end{tabular}

Note: The dependent variable is air pollution $\left(\mathrm{LCO}_{2} \mathrm{PC}\right)$. Results based on 1,159 (base model) and 987 (extended model) regressions respectively using country- and time-specific random effects. '\%Sign.' refers to the percentage of regressions in which the respective variable is significant at a $5 \%$ significance level. 'Impact rank' lists the variables in descending order according to the impact resulting from a shock of one standard deviation. The standard deviation is calculated from the between component of the variables.

In the next step, each of the remaining 18 variables, one at a time, serves as the $F$ variable in equation (1). The other 17 variables are then, in 987 combinations, used to check the robustness of the coefficient estimates of the particular $F$ variable. The results are presented in the bottom parts of Tables 1 and 2.

These tables report that two additional variables are robust determinants of both water $(\mathrm{BOD})$ and air $\left(\mathrm{CO}_{2}\right)$ pollution. These are the industry share as measured by employment (INDSHEMP) and inequality (INEQUAL). A higher industry share of total employment induces more political pressure against pro-environmental policies. Given that we control for the industry share of GDP, the result can be interpreted as showing that a more labour-intensive industry leads to more water and air pollution. Possibly, a labour-intensive industrial sector is less efficient and therefore produces more waste.

Second, both forms of pollution are robustly related to inequality (INEQUAL). Its negative effect is broadly in line with Gassebner et al. (2008) who state that 
Table 3 Descriptive statistics of the EKC turning points (in constant 1995 US \$ per capita)

\begin{tabular}{lll}
\hline & \multicolumn{1}{c}{$\mathrm{CO}_{2}$} & \multicolumn{1}{c}{ BOD } \\
\hline Average turning point & $2.53 \mathrm{E}+11$ & 61,708 \\
Median turning point & 613,547 & 26,831 \\
Turning point of avg. coeff. ${ }^{a}$ & 575,049 & 27,515 \\
Standard deviation & $3.65 \mathrm{E}+12$ & 120,000 \\
Kurtosis & 476.08 & 32.50 \\
Skewness & 20.44 & 4.91 \\
\hline
\end{tabular}

Note: Results are based on the coefficients of the 1,159 regressions of the base model.

${ }^{a}$ Represents the result when first calculating the average of the 1,159 coefficients and then calculating the turning point.

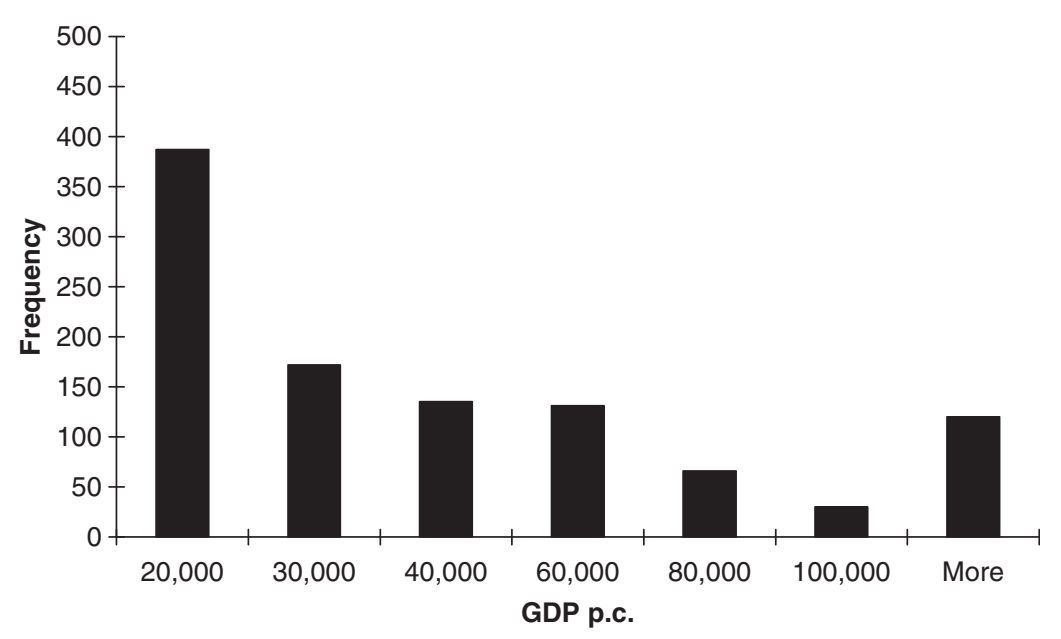

Fig. 2 Histogram of EKC turning points - water pollution (LBODPC) (in constant 1995 US \$ per capita)

Note: These frequency distributions summarize the results of the EKC turning points of the 1,159 regressions of the base model.

inequality resulting from deindustrialization and translating into diminishing political power of the industry sector, will lead to a stricter environmental policy.

Other similarities between $\mathrm{BOD}$ and $\mathrm{CO}_{2}$ are that quite a number of variables do not seem to robustly explain the observed levels of pollution. This list includes both education variables, i.e., the illiteracy rate (ILLIT) as well as primary education (PRIMEDU). Also most political-institutional variables, which recently received special attention in the literature, belong to this category. Democracy (DEMOC), political freedom (POLFREE), the duration of the executive being in office (YRSOFFC) as well as the left-wing dummy (LEFT) have no robust direct impact on either of our two pollution variables. This does not imply that politics 
do not play a role in determining pollution. It simply means that the channel might be an indirect one, e.g., by shaping the structural composition of a country's economy. ${ }^{29}$

Our pollution measures are not robustly related to the industry share of GDP (INDSHGDP). Apparently, the industry share in employment (INDSHEMP) is much more important. Moreover, neither water pollution nor air pollution are significantly related to international trade (TRADE). Hence, of the three components underlying the aggregate trade effect, the technique effect—which basically refers to the increased availability of 'greener' technologies as supported by, e.g., Cole (2004) — cannot be dominant. It appears to be overshadowed by either the scale or the composition effect, or both, which leaves an insignificant overall effect. Thus we find neither evidence for a pollution reduction effect of trade nor for the pollution haven hypothesis. Like TRADE, foreign direct investment (FDIGDP) does not appear to play a robust role with respect to either form of pollution.

Finally, the results concerning population density (LPOPDENS) suggest that more inhabitants per square kilometer do not directly and significantly affect a country's environmental quality. Urbanization (URBAN) also fails to meet the criterion of a robust variable in both cases.

There are some notable differences between the two pollution variables with respect to the significance of some of the remaining explanatory variables. First, the the two remaining political-institutional variable, i.e., the dictatorship dummy (DICT) and economic freedom (ECFREE), appear to matter but for different forms of pollution. $\mathrm{CO}_{2}$ exhibits a relatively robust negative relationship with DICT. This result appears at least partly in line with Klick (2002), who claims that improving environmental quality may be a powerful and effective way to bribe the population and secure a dictator's tenure.

With respect to economic freedom we find evidence that an unregulated economy might not produce at a level (or with a technology) which maximizes social welfare (as measured by water pollution, in this case). This is in contrast to Carlsson and Lundström (2003) who report exactly the opposite finding.

Surprisingly, water pollution is not related to fertilizer usage (LFERT) but air pollution is. While the theoretical relationship between water pollution and fertilizers seems apparent, the estimation results do not reject our reasoning to include LFERT as an explanatory variable for air pollution; LFERT might proxy either the general attitude toward environment protection, or the importance of 'dirty' industries, or both.

Besides its significance, the impact of a variable is of importance. In Tables 1 and 2 the column 'Impact rank' refers to the ranking according to the impact of a shock of one standard deviation of the respective variable on the level of

\footnotetext{
${ }^{29}$ The political system might very well determine the importance of industry and its labour intensiveness. By directly controlling for these factors we have beforehand eliminated such potential indirect effects.
} 
pollution. ${ }^{30}$ As expected, the more robust variables are in general also the ones that are quantitatively more important.

One of the objections against EBA is that all regressions get an equal weight, i.e., misspecified equations receive as much attention as others. This might bias the outcome. In order to minimize this risk, we employ White's test for general heteroscedasticity (White, 1980) and the Ramsey RESET test of functional form (Ramsey, 1969; Granger and Terasvirta, 1993; Lee et al., 1993) and exclude all potentially problematic specifications. The White test is the most general test for heteroscedasticity available, i.e., hardly any assumptions with respect to the potential form of heteroscedasticity are made. As a result the test might not only reveal the presence of heteroscedasticity but also highlight other forms of misspecification (for details see Thursby, 1982). As we are in particular interested in detecting potentially misspecified equations, this property is not a shortcoming but a virtue in our case.

The RESET test is originally designed to discover potential nonlinearities in the specification. Nowadays, it is often believed that the alternatives are not that clear cut, implying that the test may also be used to check for omitted variables as well as some forms of autocorrelation. The test regresses $\hat{u}$ on $\hat{y}^{2}, \hat{y}^{3}$, and a constant. Under the null hypothesis of no specification error the coefficients of $\hat{y}^{2}$ and $\hat{y}^{\hat{3}}$ are jointly insignificant. Although there is no consensus on what the alternative hypothesis exactly is, rejecting the null hypothesis underlying the RESET test seems to pinpoint serious specification problems.

Running the EBA and controlling for the quality of the residuals by using both of our specification tests-we use a significance level of $5 \%$-leads to the exclusion of approximately $80 \%$ and $60 \%$ of the regressions in the $\mathrm{BOD}$ and $\mathrm{CO}_{2}$ cases, respectively. ${ }^{31}$ Nevertheless, our results hardly change and all of our conclusions remain valid. Most importantly, the variables that exhibit a robust relationship to our pollution measures remain robust whereas there are no additional variables that meet our $\operatorname{CDF}(0)$ criterion.

To support our findings, we take the most robust variables and estimate 'final' models for both water and air pollution. In the BOD model five variables meet the criterion of having a $\mathrm{CDF}(0)$ of 0.95 or higher, while in the $\mathrm{CO}_{2}$ model six variables do. These variables are all included in the respective 'final' model. For BOD, each variable is highly significant and has a coefficient of the same order of magnitude as reported in the EBA tables. ${ }^{32}$ In the case of $\mathrm{CO}_{2}$, only the inequality variable turns out to be statistically insignificant at conventional levels. The results are summarized in Tables 4 and 5.

\footnotetext{
${ }^{30} \mathrm{We}$ calculate the standard deviation of the between components of the variables. Due to the nonlinearity of LGDPPC and LGDPPC ${ }^{2}$ both variables are excluded from the ranking.

${ }^{31}$ At first glance, this appears to be a lot. However, the vast majority of the excluded regressions only suffer from heteroscedasticity. Thus the resulting coefficients are unbiased.

${ }^{32}$ As, of course, this cutoff is rather arbitrary, we also experimented with a cutoff of 0.9 . The conclusions do not depend upon this and reflect the findings of the EBA, i.e., the additional variables are in general less significant.
} 
Table 4 Final model—dependent variable: water pollution (LBODPC)

\begin{tabular}{|c|c|c|c|c|}
\hline $\begin{array}{l}\text { Sample } \\
\text { variable }\end{array}$ & $\begin{array}{l}\text { (1) } \\
\text { Full sample }\end{array}$ & $\begin{array}{l}\text { (2) } \\
\text { Full sample }\end{array}$ & $\begin{array}{l}(3) \\
1990 \mathrm{~s}\end{array}$ & $\begin{array}{l}(4) \\
\text { non-OECD }\end{array}$ \\
\hline LGDPPC1 & $\begin{array}{l}2.739^{* * *} \\
(0.725)\end{array}$ & $\begin{array}{l}1.751^{* * *} \\
(0.495)\end{array}$ & $\begin{array}{l}1.824^{* * *} \\
(0.606)\end{array}$ & $\begin{array}{l}2.076^{* * *} \\
(0.508)\end{array}$ \\
\hline LGDPPCSQ1 & $\begin{array}{c}-0.158^{\star * *} \\
(0.041)\end{array}$ & $\begin{array}{c}-0.101^{* * *} \\
(0.029)\end{array}$ & $\begin{array}{c}-0.106^{* * *} \\
(0.039)\end{array}$ & $\begin{array}{c}-0.124^{\star * *} \\
(0.032)\end{array}$ \\
\hline INDSHEMP1 & $\begin{array}{l}0.016^{* * *} \\
(0.005)\end{array}$ & $\begin{array}{l}0.020^{* * *} \\
(0.005)\end{array}$ & $\begin{array}{l}0.014^{\star *} \\
(0.005)\end{array}$ & $\begin{array}{l}0.016^{* * *} \\
(0.004)\end{array}$ \\
\hline INEQUAL1 & $\begin{array}{c}-0.021^{* * *} \\
(0.008)\end{array}$ & $\begin{array}{c}-0.015^{\star * *} \\
(0.005)\end{array}$ & $\begin{array}{r}-0.010^{\star} \\
(0.005)\end{array}$ & $\begin{array}{c}-0.018^{\star * *} \\
(0.006)\end{array}$ \\
\hline ECFREE1 & $\begin{array}{l}0.064^{* * *} \\
(0.023)\end{array}$ & & & \\
\hline Observations & 204 & 941 & 576 & 562 \\
\hline Countries & 81 & 110 & 96 & 87 \\
\hline Periods & 3 & 19 & 10 & 19 \\
\hline R-Sq (within) & 0.583 & 0.458 & 0.311 & 0.490 \\
\hline F-test & 0.001 & 0.003 & 0.003 & 0.000 \\
\hline EKC T.P. & 5,812 & 5,816 & 5,452 & 4,320 \\
\hline
\end{tabular}

Note: ${ }^{\star * *},{ }^{* *}$, and ${ }^{\star}$ indicates significance at the $10 \%, 5 \%, 1 \%$-significance level.

'1990s' uses only the years 1990-99, 'non-OECD' excludes OECD countries. All estimations include country- and time-specific fixed effects. Clustered standard errors are given in parentheses below the coefficient. 'F-test' reports the p-value of an F-test on the joint significance of the coefficients of LGDPPC1 and LGDPPCSQ1. 'EKC T.P.' represents the turning point of the EKC in constant 1995 US \$ per capita.

As compared to the EBA results, the EKC turning point implied by the 'final' model for water pollution is below the median-with a point estimate of about US $\$ 5,800$ (in constant 1995 prices).

As these turning points are based on the ratio of the LGDPPC- and LGDPPC ${ }^{2}$ coefficients, potential measurement error in GDP per capita has distinctive implications as demonstrated by Kuha and Temple (2003). Given the potential sensitivity of the estimated turning point to measurement error, we calculate the confidence intervals for the marginal effects of GDP on the respective type of pollution for the final models. These income elasticities are depicted in Fig. 3. The markers represent the existing observations and the dashed lines denote the $90 \%$ confidence bands around the income elasticity. For the poorest countries in our sample, a 1\% increase of GDP per capita will increase water pollution levels by approximately $1 \%$. On the other hand, the income elasticities for the richest economies turn out to be about -0.5 . We thereby confirm the existence of the EKC for water pollution. Turning to air pollution, the estimated income elasticities range between 0.75 and 0.5 and, most importantly, never turn negative within our sample. Hence, here we can only confirm a concave relationship.

To test the robustness of the 'final' model, we check its sensitivity with respect to the sample. As the economic freedom variable seriously restricts our sample we 
Table 5 Final model—dependent variable: air pollution (LCO2PC)

\begin{tabular}{lccc}
\hline Sample & $(1)$ & $(2)$ & $(3)$ \\
variable & Full sample & $1990 \mathrm{~s}$ & non-OECD \\
\hline LGDPPC1 & $0.900^{* *}$ & $2.133^{* * *}$ & 0.313 \\
& $(0.421)$ & $(0.532)$ & $(0.494)$ \\
LGDPPCSQ1 & -0.018 & $-0.098^{* * *}$ & 0.021 \\
& $(0.025)$ & $(0.034)$ & $(0.031)$ \\
INDSHEMP1 & $0.016^{* * *}$ & $0.012^{* * *}$ & $0.019^{* * *}$ \\
& $(0.004)$ & $(0.003)$ & $(0.005)$ \\
LFERT1 & $0.109^{* * *}$ & $0.045^{* *}$ & $0.117^{* * *}$ \\
& $(0.029)$ & $(0.019)$ & $(0.035)$ \\
DICT1 & $-0.102^{*}$ & -0.012 & -0.070 \\
& $(0.056)$ & $(0.061)$ & $(0.064)$ \\
INEQUAL1 & -0.001 & -0.001 & 0.004 \\
& $(0.005)$ & $(0.004)$ & $(0.006)$ \\
Observations & 855 & 510 & 515 \\
Countries & 109 & 96 & 87 \\
Periods & 17 & 8 & 17 \\
R-Sq (within) & 0.519 & 0.412 & 0.565 \\
F-test & 0.000 & 0.000 & 0.000 \\
EKC TP & - & 53,245 & - \\
\hline
\end{tabular}

Note: ${ }^{* *},{ }^{* *}$, and ${ }^{*}$ indicates significance at the $10 \%, 5 \%$, and $1 \%$-significance level.

'1990s' uses only the years 1990-99, 'non-OECD' excludes OECD countries. All estimations include country- and time-specific fixed effects. Clustered standard errors are given in parentheses below the coefficient. 'F-test' reports the p-value of an F-test on the joint significance of the coefficients of LGDPPC1 and LGDPPCSQ1. 'EKC TP' represents the turning point of the EKC in constant 1995 US $\$$ per capita.

reestimate the model leaving it out. This leaves all our findings unchanged. Moreover, we reduce the sample to only cover the 1990s. Arguably, the world has changed considerably and it appears that environmental awareness has increased as compared to the 1960s and 1970s. Finally, we split the sample across the country dimension by excluding OECD countries. One can argue that developed and less developed countries are too different to be included in one setup; pooling these two groups may lead to biased coefficient estimates. In particular, the within variation of GDP per capita could differ greatly between OECD and nonOECD countries. As Tables 4 and 5 show our conclusions remain rather similar. One exception is dictatorship (DICT) for air pollution which turns insignificant when focusing on the 1990s or the non-OECD countries. Furthermore, although the implied turning point is still out of sample, we now do find somewhat stronger evidence for a concave relationship between income and air pollution for the 1990s.

\section{Conclusions}

Environmental quality continues to draw the attention of economists and society as a whole. Recently, the discussion in the academic literature has started to focus on 


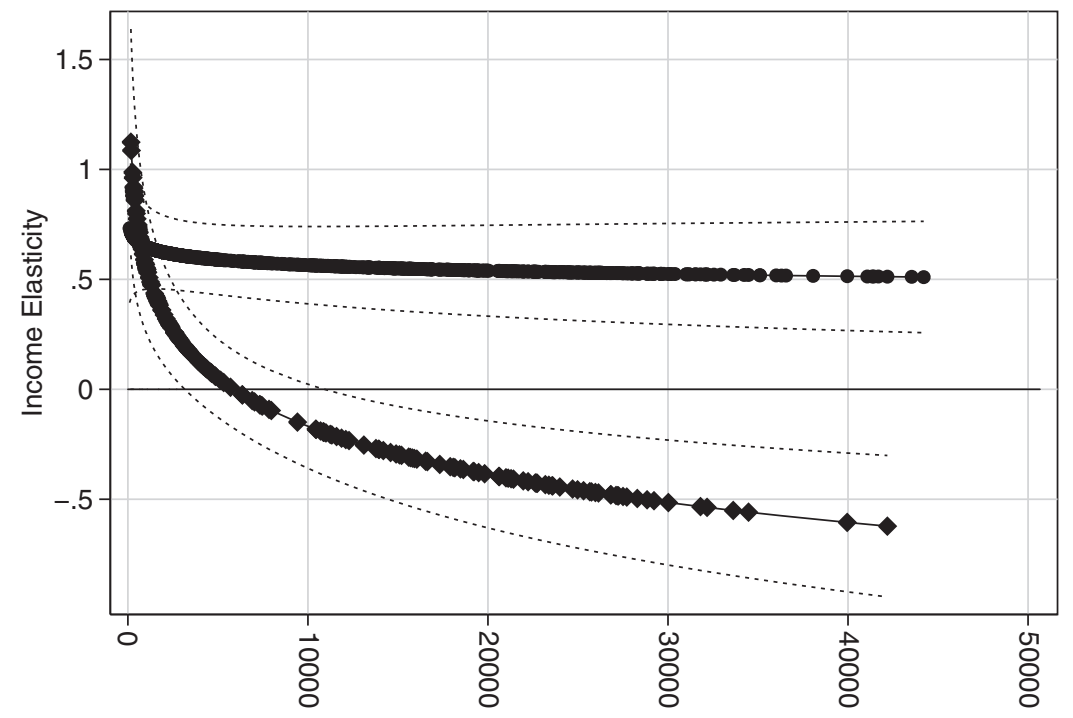

GDP p.c., constant 1995 US\$

Fig. 3 Per capita income elasticity of pollution (in constant 1995 US \$)

Note: The figure is based on the results displayed in Tables 4 and 5, column (1). Dashed lines denote $90 \%$ confidence bands. Markers represent existing observations for water pollution (circles) and air pollution (diamonds).

political-institutional factors possibly determining pollution levels. Despite empirical research investigating the impact of various economic, political, and demographic factors on pollution, however, there is no consensus over which of these forces actually matter. This casts doubt on the general robustness of published results. The present paper provides an overview and a thorough robustness analysis of these and other determinants of pollution.

A first result, in line with the literature, is that we endorse the existence of an environmental Kuznets curve for water pollution. Using various specifications, a quadratic set-up correlating prosperity with water pollution suggests an inverted U-shaped relationship within sample. Our estimated median turning point-US $\$ 26,800$ per capita GDP (in constant 1995 prices)—has already been reached by several countries in our sample. In contrast, we find no evidence for the existence of an EKC for air pollution. For levels of per capita GDP that are actually observed in sample, no more than a concave relationship is found. From a policy point of view, this suggests that it would be naive to bet on reaching a turning point which might only be a statistical artifact. We have hardly any evidence that the air pollution problem will solve itself and thus direct action may be required. In contrast to the literature, this conclusion is supported by the analysis of thousands of different models. 
Second, a number of variables related to the economic structure of a country matter for its environmental quality. Especially employment-based indicators of industrialization are highly significant and have the expected (positive) sign. Furthermore, fertilizer consumption per hectare of arable land significantly explains $\mathrm{CO}_{2}$ emission levels around the world.

Third, openness - as measured by the ratio of total trade over GDP-is not related to the pollution level of an economy. Apparently, the claim that access to 'greener' technologies caused by globalization would lead to an improvement of environmental quality is difficult to maintain. However, there does not seem to be evidence in favour of the pollution haven hypothesis, either.

Fourth, demographic factors seem to be of minor importance.

Fifth, inequality increases environmental quality. In contrast to the mostly negative association so far in the literature, we confirm more recent model predictions which state that there are indeed beneficial side-effects of income inequality on the environmental quality. For instance, the declining importance of blue-collar workers might tend to increase environmental regulation.

Sixth, recent interest in more politically motivated explanations of environmental quality does not appear to be a very promising path. In fact, only our dictatorship dummy appears robustly related to $\mathrm{CO}_{2}$ emissions; dictatorships are associated with less air pollution per capita. Also, economic freedom seems to increase water pollution. However, we have to admit that, due to the reduced form characteristics of our set-up, this does not imply that there are no indirect channels through which these political variables influence pollution.

It is important to point out some limitations of our approach. Our focus was to provide an empirical assessment of previously proposed variables. It is well known that focusing on reduced form estimations has the advantage of easy-to-obtain, clear-cut results. However, this comes at the cost of potentially missing some indirect transmission channels, or not being able to model the underlying dynamics in a more sophisticated way. Therefore, further research in this field should, on the one hand, reconsider and maybe blend some of the theoretical models that lead to the inclusion of some of the variables we identify to be robust. On the other hand, our results can be used as a starting point for setting up and estimating more structurally based models that are able to capture potential indirect effects and deal with the underlying dynamics. Hence, even though we believe our work is a major step forward, there is still much more to be done in this field of research.

\section{Supplementary material}

Supplementary material (Appendix 2, Tables A3 and A4) is available online at the OUP website.

\section{Acknowledgements}

An earlier version of the paper was entitled 'Economic, Demographic and Political Determinants of Pollution Reassessed: A Sensitivity Analysis.' We thank participants of 
the following conferences and workshops for providing valuable suggestions: XII Conference on Public Economics, Palma de Mallorca; Macroeconomic Research Meeting, Kreuzlingen; Swiss Society for Economics and Statistics Meeting, Zurich; European Public Choice Society Meeting, Durham; Augustin Cournot Doctoral Days, Strasbourg; 14th Silvaplana Workshop on Political Economy, Silvaplana.

\section{References}

Aidt, T. and Gassebner, M. (2010) Do autocratic states trade less? World Bank Economic Review, 24, 38-76.

Antle, J.M. and Heidebrink, G. (1995) Environment and development: theory and international evidence, Economic Development and Cultural Change, 43, 603-25.

Antweiler, W., Copeland, B.R., and Taylor, M.S. (2001) Is free trade good for the environment? American Economic Review, 91, 877-908.

Arrow, K., Bolin, B., Constanza, R., Dasgupta, P., Folke, C., Holling, C.S., Jansson, B.-O., Levin, S., Maler, K.-G., Perrings, C., and Pimental, D. (1995) Economic growth, carrying capacity and the environment, Ecological Economics, 15, 91-5.

Azomahou, T., Laisney, F., and Nguyen Van, P. (2006) Economic development and $\mathrm{CO}_{2}$ emissions: a nonparametric panel approach, Journal of Public Economics, 90, 1347-63.

Barrett, S. (1994) Self-enforcing international environmental agreements, Oxford Economic Papers, 46, 878-94.

Beck, T., Clarke, G., Groff, A., Keefer, P., and Walsh, P. (2001) New tools in comparative political economy: the database of political institutions, World Bank Economic Review, 15, 165-76.

Begun, J. and Eicher, T.S. (2008) In search of an environmental Kuznets curve in sulphur dioxide concentrations: a Bayesian model averaging approach, Environment and Development Economics, 13, 795-22.

Bernauer, T. and Koubi, V. (2009) Effects of political institutions on air quality, Ecological Economics, 68, 1355-65.

Beugelsdijk, S., de Groot, H.L., and van Schaik, A.B. (2004) Trust and economic growth: a robustness analysis, Oxford Economic Papers, 56, 118-34.

Birdsall, N. and Wheeler, D. (1993) Trade policy and industrial pollution in Latin America: where are the pollution havens? Journal of Environment and Development, 2, 137-49.

Borghesi, S. (2006) Income inequality and the environmental Kuznets curve, in M. Basili, M. Franzini, and A. Vercelli (eds) Environment, Inequality and Collective Action, Routledge, London, 33-51.

Caplan, A.J., Cornes, R.G., and Silva, E.C.D. (2003) An ideal Kyoto protocol: emissions trading, redistributive transfers and global participation, Oxford Economic Papers, 55, 216-34.

Carlsson, F. and Lundström, S. (2003) The effects of economic and political freedom on $\mathrm{CO}_{2}$ emissions, Working Papers in Economics 29, Department of Economics, Goteborg University.

Chamon, M., Mauro, P., and Okawa, Y. (2008) Mass car ownership in the emerging market giants, Economic Policy, 23, 243-96.

Cole, M.A. (2004) Trade, the pollution haven hypothesis and the environmental Kuznets curve: examining the linkages, Ecological Economics, 48, 71-81. 
Cole, M.A. and Elliott, R.J.R. (2003) Determining the trade-environment composition effect: the role of capital, labor and environmental regulations, Journal of Environmental Economics and Management, 46, 363-83.

Cole, M.A., Elliott, R.J.R., and Fredriksson, P.G. (2006) Endogenous pollution havens: does FDI influence environmental regulations? Scandinavian Journal of Economics, 108, $157-78$.

Cole, M.A. and Neumayer, E. (2004) Examining the impact of demographic factors on air pollution, Population and Environment, 26, 5-21.

Congleton, R.D. (1992) Political institutions and pollution control, Review of Economics and Statistics, 74, 412-21.

Copeland, B.R. and Taylor, M.S. (2004) Trade, growth, and the environment, Journal of Economic Literature, 42, 7-71.

Damania, R., Fredriksson, P.G., and List, J.A. (2003) Trade liberalization, corruption, and environmental policy formation: theory and evidence, Journal of Environmental Economics and Management, 46, 490-12.

Dinda, S. (2004) Environmental Kuznets curve hypothesis: a survey, Ecological Economics, 49, 431-55.

Frankel, J.A. and Rose, A.K. (2005) Is trade good or bad for the environment? Sorting out the causality, Review of Economics and Statistics, 87, 85-91.

Freedom House (1999) Annual Survey of Freedom Country Scores 1972-1973 to 1998-1999, Freedom House, Washington, DC.

Gassebner, M., Gaston, N., and Lamla, M.J. (2008) Relief for the environment? The importance of an increasingly unimportant industrial sector, Economic Inquiry, 46, 160-78.

Gassebner, M., Lamla, M.J., and Sturm, J.-E. (2006) Economic, demographic and political determinants of pollution reassessed: a sensitivity analysis, KOF Working Papers 129 KOF Swiss Economic Institute, ETH Zurich.

Granger, C.W.J. and Terasvirta, T. (1993) Modelling Nonlinear Economic Relationships, Oxford University Press, Oxford.

Grossman, G.M. and Krueger, A.B. (1995) Economic growth and the environment, Quarterly Journal of Economics, 110, 353-77.

Gurr, T., Jaggers, K., and Moore, W. (2003) Polity Handbook IV, University of Colorado Press, Boulder, CO.

Gwartney, J., Lawson, R., and Samida, D. (2003) Economic Freedom in the World: 2003 Annual Report, Fraser Institute, Vancouver.

Holtz-Eakin, D. and Selden, T. (1995) Stoking the fires? $\mathrm{CO}_{2}$ emissions and economic growth, Journal of Public Economics, 57, 85-101.

Jaffe, A.B., Peterson, S.R., Portney, P.R., and Stavins, R.N. (1995) Environmental regulation and the competitiveness of US manufacturing: what does the evidence tell us? Journal of Economic Literature, 33, 132-63.

Klick, J. (2002) Autocrats and the environment or it's easy being green, Law \& Economics Research Paper 02-16, George Mason University, Washington, DC.

Kuha, J. and Temple, J. (2003) Covariate measurement error in quadratic regression, International Statistical Review, 71, 131-50. 
Kuznets, S. (1955) Economic growth and income inequality, American Economic Review, 45, $1-28$.

Lamla, M.J. (2009) Long-run determinants of pollution: a robustness analysis, Ecological Economics, 69, 135-44.

Leamer, E.E. (1983) Let's take the con out of econometrics, American Economic Review, 73, $31-43$.

Lee, T.H., White, H., and Granger, C.W.J. (1993) Testing for neglected non-linearities in time series models: a comparison of neural network methods and alternative tests, Journal of Econometrics, 56, 269-90.

Levine, R. and Renelt, D. (1992) A sensitivity analysis of cross-country growth regressions, American Economic Review, 82, 942-63.

Lipset, S.M. (1959) Some social requisites of democracy: economic development and political legitimacy, American Political Science Review, 53, 69-105.

Maddala, G.S. and Wu, S. (1999) A comparative study of unit root tests with panel data and a new simple test, Oxford Bulletin of Economics and Statistics, 61, 631-52.

Maddison, D. (2006) Environmental Kuznets curves: a spatial econometric approach, Journal of Environmental Economics and Management, 51, 218-30.

Mani, M. and Wheeler, D. (1998) In search of pollution havens? Dirty industry in the world economy, 1960-1995, Journal of Environment and Development, 7, 215-47.

McAusland, C. (2003) Voting for pollution policy: the importance of income inequality and openness to trade, Journal of International Economics, 61, 425-51.

McGinty, M. (2007) International environmental agreements among asymmetric nations, Oxford Economic Papers, 59, 45-62.

Millimet, D.L., List, J.A., and Stengos, T. (2003) The environmental Kuznets curve: real progress or misspecified models? Review of Economics and Statistics, 85, 1038-47.

Neumayer, E. (2003) Are left-wing party strength and corporatism good for the environment? Evidence from panel analysis of air pollution in OECD countries, Ecological Economics, 45, 203-20.

Neumayer, E. (2004) The environment, left-wing political orientation and ecological economics, Ecological Economics, 51, 167-75.

Raftery, A.E. (1995) Bayesian model selection in social research, Sociological Methodology, 25, 111-63.

Raftery, A.E., Madigan, D., and Hoeting, J.A. (1997) Bayesian model averaging for linear regression models, Journal of the American Statistical Association, 92, 179-91.

Ramsey, J. (1969) Tests for specification errors in classical least-squares regression analysis, Journal of the Royal Statistical Society B, 31, 350-71.

Rubio, S.J. and Ulph, A. (2006) Self-enforcing international environmental agreements revisited, Oxford Economic Papers, 58, 233-63.

Sala-i-Martin, X. (1997) I just ran two million regressions, American Economic Review, 87, 178-83.

Sala-i-Martin, X., Doppelhofer, G., and Miller, R.I. (2004) Determinants of long-term growth: a Bayesian averaging of classical estimates (BACE) approach, American Economic Review, 94, 813-83. 
Selden, T.M. and Song, D. (1994) Environmental quality and development: is there a Kuznets curve for air pollution emissions? Journal of Environmental Economics and Management, 27, 147-62.

Shafik, N. (1994) Economic development and environmental quality: an econometric analysis, Oxford Economic Papers, 46, 757-73.

Stern, D.I. (2005a) Beyond the environmental Kuznet curve: diffusion of sulfur-emissionsabating technology, Journal of Environment and Development, 14, 101-24.

Stern, D.I. (2005b) Global sulfur emmissions from 1850 to 2000, Chemosphere, 58, 163-75.

Stern, D.I. and Common, M.S. (2001) Is there an environmental Kuznets curve for sulfur? Journal of Environmental Economics and Management, 41, 162-78.

Sturm, J.-E. and de Haan, J. (2005) Determinants of long-term growth: new results applying robust estimation and extreme bounds analysis, Empirical Economics, 30, 597-617.

Temple, J. (2000) Growth regressions and what the textbooks don't tell you, Bulletin of Economic Research, 52, 181-205.

Thursby, J. (1982) Misspecification, heteroscedasticity, and the Chow and Goldfeld-Quandt tests, Review of Economics and Statistics, 64, 314-21.

Torras, M. and Boyce, J.K. (1998) Income, inequality, and pollution: a reassessment of the environmental Kuznets curve, Ecological Economics, 25, 147-60.

University of Texas Inequality Project (2001) UTIP-UNIDO dataset. http://utip.gov.utexas .edu/data/UTIPUNIDO2001rv3.xls.

Vreeland, J.R. (2008) The effect of political regime on civil war: unpacking anocracy, Journal of Conflict Resolution, 52, 401-25.

White, H. (1980) A heteroskedasticity-consistent covariance matrix and a direct test for heteroskedasticity, Econometrica, 48, 817-38.

World Bank (2003a). World Development Indicators, World Bank, Washington, DC.

World Bank (2003b). World Development Report, World Bank, Washington, DC. 


\section{Appendix 1}

Table A1 List of variables and their sources

\begin{tabular}{|c|c|c|c|}
\hline Variable & Sign & Description & Source \\
\hline LBODPC & & Log of $B O D$ (grams per day) per capita & WDI (2003) \\
\hline $\mathrm{LCO}_{2} \mathrm{PC}$ & & $\begin{array}{l}\text { Log of } \mathrm{CO}_{2} \text { Emissions (metric tons) per } \\
\text { capita }\end{array}$ & WDI (2003) \\
\hline $\mathrm{LSO}_{2} \mathrm{PC}$ & & $\begin{array}{l}\text { Log of } \mathrm{SO}_{2} \text { Emissions (metric tons) per } \\
\text { capita }\end{array}$ & Stern $(2005 b)$ \\
\hline DEMOC & - & $\begin{array}{l}\text { Democracy Score: general openness of } \\
\text { political institutions }\end{array}$ & Gurr et al. (2003) \\
\hline DICT & $?$ & $\begin{array}{l}\text { Dummy variable for dictatorship (execu- } \\
\text { tive index of electoral competitiveness } \\
<3 \text { ) }\end{array}$ & Beck et al. (2001) \\
\hline ECFREE & - & Fraser Economic Freedom Index & Gwartney et al. (2003) \\
\hline FDIGDP & $?$ & $\begin{array}{l}\text { Net inflows of foreign direct investment } \\
\text { (\% of GDP) }\end{array}$ & WDI (2003) \\
\hline GDPGR & ? & GDP growth rate (annual \%) & WDI (2003) \\
\hline ILLIT & + & $\begin{array}{l}\text { Adult illiteracy rate (\% of people ages } 15 \\
\text { and above) }\end{array}$ & WDI (2003) \\
\hline INDSHEMP & + & $\begin{array}{l}\text { Employment in industry (\% of total } \\
\text { employment) }\end{array}$ & WDI (2003) \\
\hline INDSHGDP & + & Manufacturing value added ( $\%$ of GDP) & WDI (2003) \\
\hline INEQUAL & ? & Industrial pay-inequality measure & UTIP (2001) \\
\hline LEFT & $?$ & $\begin{array}{l}\text { Dummy variable for the party of the chief } \\
\text { executive being left-wing }\end{array}$ & Beck et al. (2001) \\
\hline LFERT & + & $\begin{array}{l}\text { Log of fertilizer use (100 grams per hec- } \\
\text { tare of arable land) }\end{array}$ & WDI (2003) \\
\hline LGDPPC & + & $\begin{array}{l}\text { Log of GDP (constant } 1995 \text { US \$) per } \\
\text { capita }\end{array}$ & WDI (2003) \\
\hline LGDPPCSQ & - & Squared log of real GDP per capita & WDI (2003) \\
\hline LGDPPCCB & $?$ & Cubic log of real GDP per capita & WDI (2003) \\
\hline LPOPDENS & $?$ & Log of population per hectare & WDI (2003) \\
\hline OILENERGY & + & $\begin{array}{l}\text { Electricity production from oil sources } \\
\text { (\% of total) }\end{array}$ & WDI (2003) \\
\hline POLFREE & - & $\begin{array}{l}\text { Average of the two Freedom House } \\
\text { indices }\end{array}$ & FHI (1999) \\
\hline PRIMEDU & - & $\begin{array}{l}\text { Gross primary school enrollment ( } \% \text { of } \\
\text { corresponding age group) }\end{array}$ & WDI (2003) \\
\hline TRADE & $?$ & Trade intensity ((import+export)/GDP) & WDI (2003) \\
\hline URBAN & $?$ & Urban population ( $\%$ of total) & WDI (2003) \\
\hline YRSOFFC & + & $\begin{array}{l}\text { Number of years chief executive has been } \\
\text { in office }\end{array}$ & Beck et al. (2001) \\
\hline
\end{tabular}

Note: Variables are sorted alphabetically. 'Sign' refers to the expected sign: '+/-' denotes a positive/ negative relation according to the literature while '?' denotes an a priori ambiguous effect. 


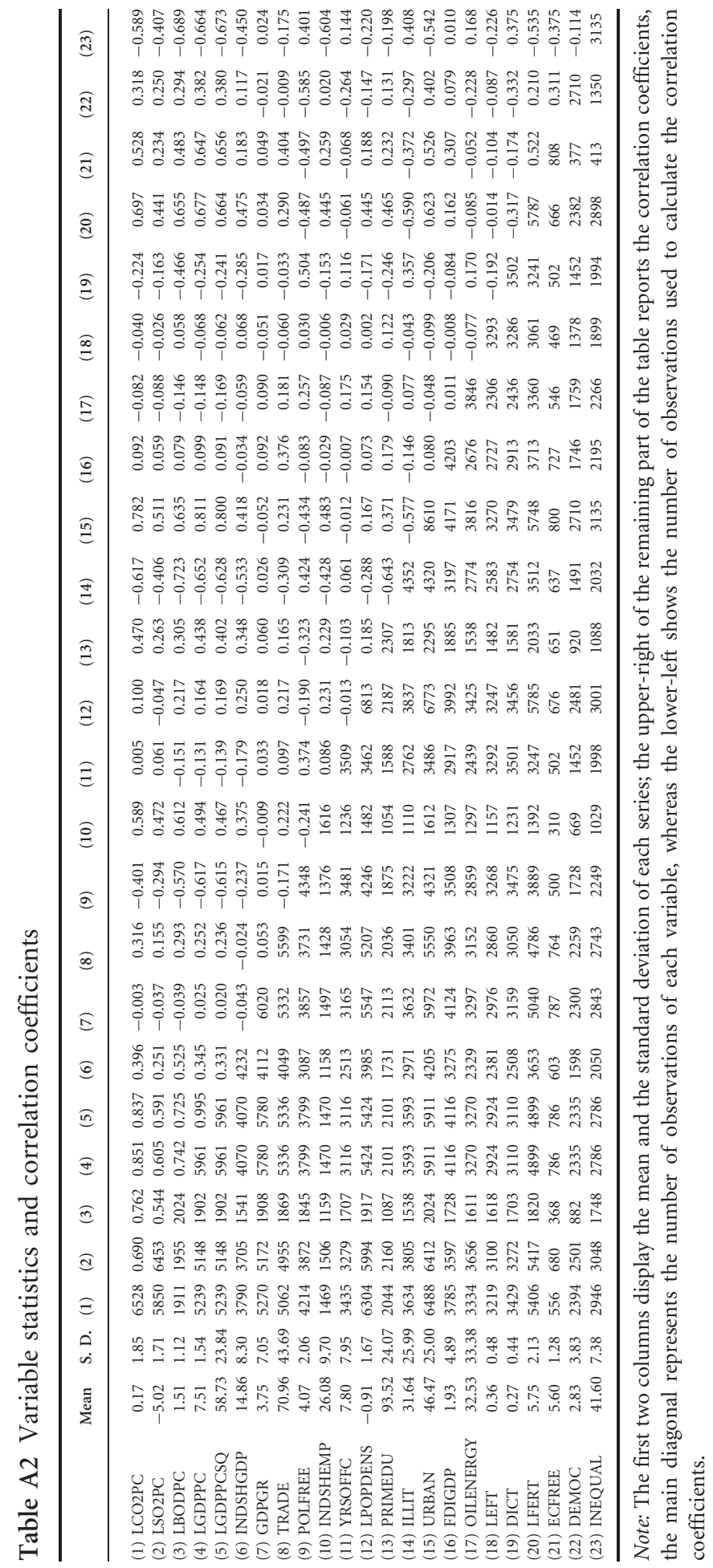

